\title{
24TH COLLEGIUM RAMAZZINI STATEMENT PREVENTION OF WORK-RELATED INFECTION IN THE COVID-19 PANDEMIC
}

The Collegium Ramazzini is an independent, international society comprised of 180 physicians and scientists from 35 countries. Its mission is to increase scientific knowledge of the environmental and occupational causes of disease and to transmit this knowledge to decision-makers, the media and the global public to prevent disease, promote health and save lives.

The Collegium Ramazzini calls urgently for preventive measures internationally and in every country to reduce risk of COVID-19 infection in workers.

The COVID-19 pandemic has affected every country in the world, caused confirmed illness in more than 3 million people, unconfirmed disease in millions more, and more than 200000 deaths. At present, there is no vaccine and no medical treatment for COVID-19. Pandemic control must therefore rely entirely on measures that reduce the spread of infection, flatten the epidemic curve, and gain time to develop more effective responses.

Workers whose occupations put them in contact with infected persons and the public are at greatly increased risk of disease and death and have suffered disproportionately in the COVID-19 pandemic. Workplaces have repeatedly been the source of serious outbreaks.

Protection of all workers, and especially workers who continue to provide essential services during the pandemic as well as vulnerable workers, must be a top priority at every stage.

High-Risk Workers. Workers whose occupations put them in contact with infected persons and the public are at greatly increased risk of COVID-19 infection. These workers require heightened protection. A partial listing of high-risk workers is the following:

- Very High Risk: health care workers, paramedics, police, firefighters airline personnel, transport workers, drivers, sales and service personnel, cleaners, mortuary workers, migrant workers, volunteers, and religious professionals.

- High Risk: security service workers; hotel and food service workers; cruise industry workers; and military personnel pressed into pandemic service; workers in infrastructure, manufacturing, meatpacking, construction, mining and other occupations with crammed workplaces and poor provision of occupational and personal hygiene measures.

- Workers at Increased Vulnerability: older workers, workers with underlying medical conditions, workers occupationally exposed to dusts, gases and fumes, workers of low socio-economic status, workers in developing countries, and workers exposed to high levels of ambient air pollution.

The Collegium Ramazzini calls on governments at all levels - national, state or provincial, and local - and on all employers - large and small, public and private - to fulfill their responsibilities to protect the health of all workers in the COVID-19 pandemic. 


\section{Responsibilities of Governments}

Strengthen and Maintain Public Health Systems. Governments have responsibility to protect workers' health and the health of populations by 1) maintaining disease surveillance systems that track the spread of disease and obtain information on the industry and occupation of each sick and injured worker; 2) supporting epidemic intelligence services and laboratories that warn of impending pandemics; 3 ) organizing and leading responses to prevent disease and death; and 4) communicating accurate, evidence-based information to the public that openly acknowledges limits and uncertainties in current knowledge.

Maintain Comprehensive Social Insurance Systems. Governments have a responsibility to protect the health of workers by sustaining comprehensive social insurance systems that include health insurance; unemployment insurance; contributions to the pension system; and provision of wages and benefits during illness and isolation. Workers must be permitted to report sick and enter quarantine without fear of losing wages or benefits. All workers must be covered by such systems, including those in precarious working conditions such as migrant workers, volunteers and the selfemployed.

Enforce Regulations. Governments have a responsibility to ensure that all employers fulfill their legal and moral duty to care for their workers. Governments must ensure that employers protect their workers against occupationally acquired infection as well as against occupational and environmental exposures that increase risk of infection and severity of disease. Governments are not relieved of these responsibilities during pandemics.

Establish Presumption Policies. Governments can further protect the health of workers and the population by officially defining COVID-19 infection as an occupational disease and establishing the presumption that any COVID-19 infection in a worker in a high-risk occupation orindustry is work-related.

Pandemic Preparation. Governments must prepare for future pandemics by investing in public health and occupational health programs, maintaining disease surveillance systems, and maintaining adequate stockpiles of emergency medicines and critical supplies.

Post-Pandemic Planning. As numbers of new cases decline in the late stages of a pandemic, governments must develop protocols for systematically relaxing infection control procedures and reopening schools and businesses, beginning with lower-risk activities. These protocols must monitor numbers of new cases and the availability pf medical resources, continuously calibrate the pace of restart until a vaccine or an effective treatment has become widely available, and be prepared to pause reopening if a new wave of infections emerges. During this phase, governments must continue to sustain comprehensive social insurance systems that protect workers from unemployment, job instability and stress caused by the pandemic.

\section{Responsibilities of Employers}

Employers have a legal and moral duty to protect their workers against occupationally acquired COVID-19 infection. Employers are not relieved of these responsibilities during pandemics. Specific duties of employers in all at-risk industries are the following: 
Develop an Infectious Disease Preparedness and Response Plan. This is a key component of pandemic planning and preparation. It includes designation of an infection control officer; provision of training to all at-risk workers; eliminating adverse working conditions that predispose to spread of infection, such as crowding and extreme work hours; and development of pandemic contingency plans for staggered work shifts, provision of meals and teleworking. Pandemic preparation by employers parallels pandemic planning by governments and the two must link.

Implement Basic Infection Control Measures. These include regularly disinfecting common areas and shared equipment and tools: sneezing and coughing etiquette; frequent handwashing; and physical separation during work hours and in breaks.

Establish Disease Identification and Isolation Policies. Develop policies and procedures for prompt identification, testing and isolation of workers with known or suspected infection.

Reduce hazardous occupational exposures. Reduce occupational exposures to dusts, gases and fumes that increase risk of infection.

Provide Appropriate Exposure Controls. Engineering and administrative controls must be given highest priority. Personal Protective Equipment (PPE) and behavioral controls are used only when and if there is no other feasible option.

Support Effective Personal Protective Equipment (PPE) Programs. Effective PPE programs not only provide equipment, but also include training, selection, proper use, disposal, and disinfection of all PPE items.

Restrict Unnecessary Travel. Establish travel policies that allow only necessary travel and require isolation of all travelers for 14 days upon return fromany domestic or international air travel, except for travelers documented by antibody testing to have immunity against COVID-19.

Communication. Communicate accurate, evidence-based information to workers openly and frequently through a single spokesperson, ideally the infection control officer.

Exceptions for Immunity. Exceptions may be made for workers who are found to have immunity against COVID-19.

Further elaboration is provided in the attached Technical Appendix and its Annexes.

$* * * * *$

The COVID-19 pandemic has demonstrated a woeful lack of preparedness in many governments, health care organizations and employers. This is the consequence of decades of neglect of public health and occupational health. Staffs of health agencies have been cut and budgets slashed. Emergency stockpiles of medications and supplies have been disbanded. Training has been neglected. Contingency plans have not been developed. Leadership capacity has eroded. We are all paying the price of this neglect. Workers are paying the highest price. 


\section{TECHNICAL APPENDIX \\ 24TH COLLEGIUM RAMAZZINI STATEMENT \\ PREVENTION OF WORK-RELATED INFECTION IN THE COVID-19 PANDEMIC}

\section{INTRODUCTION}

Pandemics have plagued humankind throughout history. Risk of emergence and rapid global spread of new pandemics is very high in the present age, because the world is more highly interconnected than ever before and people are moving into previously uninhabited areas of the planet and encountering pathogens that were previously sequestered. HIV/AIDS, SARS, MERS, H1N1 and EVD are all examples of infections that have emerged in recent decades and spread globally.

Workers who, during a pandemic, care for the sick, serve as first responders, and work in occupations where they have continuing exposure to the public are at high risk of acquiring new infections and of acquiring them early. It is essential that such workers be regarded in occupational safety and health programs as high-risk workers and that they be provided safe workplaces, regularly updated training, and appropriate Personal Protective Equipment (PPE). Employers have legal and moral duty to provide these safeguards to workers. Governments have responsibility to ensure that employers provide such safeguards and that they provide every worker a safe and healthful workplace.

Governments have responsibility to support public health and occupational health systems that can provide early warning of emerging infections, track the spread of pandemics, and prevent and contain infectious diseases. Public health programs need to be competently led by trained professionals, adequately staffed and sustainably funded. Like roads and bridges, aqueducts and sewer lines, public health and occupational health are essential components of the infrastructure of modern societies. Societies that neglect public health do so at their peril.

\section{Abbreviations}

COVID-19. Novel Corona Virus Disease 2019

CoV. Corona virus.

EVD. Ebola Virus Disease

H1N1. Influenza A virus Subtype H1N, aka Swine Flu

HIV. Human Immunodeficiency Virus. The virus that causes AIDS.

MERS. Middle East Respiratory Syndrome

SARS. Severe Acute Respiratory Syndrome

SARS-CoV. The virus that causes SARS

SARS-CoV-2. The virus that causes COVID-19 


\section{THE COVID-19 PANDEMIC}

Severe Acute Respiratory Syndrome Coronavirus 2 (SARS-CoV-2), the causative agent of the COVID-19 pandemic, is a zoonotic (animal) virus, a member of a large family of coronaviruses found in camels, cattle, cats, and bats and other animals. Occasionally, coronaviruses "jump" from other animals to humans and then spread in human populations ${ }^{1}$. In the 2002 SARS pandemic, for example, SARS-CoV, the causative agent, was transmitted from bats to civet cats to humans. Likewise in the 2012 MERS pandemic, MERS-CoV spread from bats to dromedary camels to humans. SARS$\mathrm{CoV}-2$ appears to have originated in bats and then passed to humans via an unconfirmed intermediary species possibly in an animal market².

SARS-CoV-2 is spread mainly through coughing and sneezing, which generate airborne infected droplets of varying sizes, including fine aerosols ${ }^{4}$. These droplets may land on mucosal surfaces - nose, mouth, and eyes - of nearby persons. Droplets may land also on surfaces and can remain viable for as long as several days depending on the surface ${ }^{9}$. Physical contact with SARS-CoV-2-contaminated surfaces and with the skin of infected persons is a significant route of transmission. Airborne transmission of SARS-CoV-2 aerosols have recently been demonstrated in laboratory experiments.

SARS-CoV-2 enters the body though inhalation. Lungs and airways that have been damaged by personal exposures such as smoking or vaping, by toxic environmental exposures such as $\mathrm{PM}_{2.5}$ air pollution ${ }^{6}$, or by occupational exposures such as silica dust, asbestos, coal dust, fumes and gases are at heighted risk of infection, severe and death ${ }^{7-9}$.

Symptoms and signs of SARS-CoV-2 infection include fever, cough, shortness of breath, and difficulty in breathing. In more severe cases, pneumonia, severe acute respiratory syndrome, cardiac impairment, kidney failure and death can ensue. Older populations and persons with underlying medical conditions, including autoimmune diseases, hypertension, diabetes, cardiovascular disease, kidney disease, chronic respiratory disease and cancer are at especially high risk ${ }^{10}$. Overall, $45 \%$ of hospitalizations and $80 \%$ of deaths associated with COVID-19 have occurred among adults aged 65 years and over. The highest prevalence of severe outcomes has been seen among persons aged 85 years and above ${ }^{11}$. Men appear to be more likely than women to develop severe COVID-19 disease ${ }^{12}$.

\section{OCCUPATIONAL EXPOSURE AND SARS-CoV-2 INFECTION}

Workers whose occupations place them in contact with persons infected by SARS-CoV-2 are at heightened risk of work-related COVID-19 infection. Data obtained in Singapore early in the outbreak in that country found that $68 \%$ of cases were spread through work-related exposures ${ }^{13}$. In many communities since then, major outbreaks have occurred in workplaces with inadequate infectious disease control procedures ${ }^{14}$.

Older workers, workers with underlying medical conditions, workers occupationally exposed to dusts, gases and fumes, workers with of low socio-economic status ${ }^{15}$, workers in developing countries, and workers exposed to high levels of ambient air pollution.

Workers at high risk of COVID-19 infection include health care workers, first responders, airline personnel, drivers, construction laborers, sales and service workers, cleaners, military personnel pressed into pandemic service, and reli- 
gious professionals. Because of their occupational exposures, these groups are at particular risk of infection in the early phases of an outbreak when most members of the population are still unexposed.

\section{List of Industries/Occupations Known to be Associated with Increased Risk of COVID-19 and related mortality}

- Very High Risk: health care workers, paramedics, police, firefighters, airline personnel, transport workers, drivers, sales and service personnel, cleaners, mortuary workers, migrant workers, religious professionals.

- High Risk: security service workers, hotel and food service workers, cruise industry workers, military personnel pressed into pandemic service.

- Significantly Increased Risk: infrastructure, manufacturing, meatpacking, construction and mining workers.

\section{Very High Risk Industries/Occupations}

\section{First Responders}

Fire fighters, emergency medical personnel and security personnel who provide pre-hospital care including patient transport can be exposed to the SARS-CoV-2 through inhalation of aerosolized droplets from infected patients' coughs and sneezes. They can also be exposed through aerosol-creating procedures, such as intubation as well as through contact with contaminated surfaces with subsequent transfer to the mouth, nose or eyes. Police officers and other law enforcement workers can be exposed though close contact in law enforcement activities and in the current pandemic while assisting in pre-hospital care as well as enforcing social distancing and shelter-in-place measures.

\section{Health Care Workers}

Workers who provide direct care health care and the many categories of workers who support them have long been recognized to be at high risk of contracting infectious diseases ${ }^{16}$. Among the 8000 persons known to have been infected affected with SARS in 29 countries, more than $20 \%$ were health workers ${ }^{17}$. These include clinical workers as well as support staff ${ }^{18}$. Likewise, emergence of the Middle East respiratory syndrome coronavirus (MERS-CoV) in 2012 was associated with high numbers of infections in health care workers, with many cases associated with "super-spreader" events ${ }^{19,20}$. Most recently, Ebola Virus Disease was seen to affect health workers at a rate more than a ten times higher than community members ${ }^{21}$.

As of February 16, 2020, health care workers accounted for $4.3 \%$ of reported and 4.8\% of confirmed COVID-19 cases in China ${ }^{22}$. Early spread of COVID-19 in the United States from infected but largely asymptomatic health care workers resulted from these workers being rotated among different facilities ${ }^{23}$. As of April 9, 2020, 9282 U.S. health care personnel with confirmed COVID-19 had been reported to CDC. This is likely an undercount of the true number because HCP status was available for only $16 \%$ of reported cases nationwide, and because mild cases and asymptomatic cases are less likely to be tested and reported ${ }^{24}$. 


\section{Mortuary Services Workers}

Morticians and other funeral workers who handle potentially infected decedents are known from other outbreaks (e.g., EVD) to have a very high risk of infection. Funeral workers' exposures occur during bagging, transfer, and embalming and may continue during funeral viewing services, when they have contact with family members and close contacts who may be infected with the virus.

\section{Migrant Workers}

Migrant workers comprise a large share of the global workforce. Because of the nature of their work they are at very high of contracting infectious diseases, and also for transmitting them ${ }^{25}$ between areas, regions and nations ${ }^{26}$. As of this writing, large numbers of crew members are stuck on laid-up cruise ships, some with COVID-19 outbreaks, and nowhere to go. In Singapore, an outbreak of COVID-19 occurred in migrant worker camps ${ }^{27}$.

\section{High Risk Industries/Occupations}

Transportation workers are at very high risk of contracting the SARS-CoV-2 virus. At the peak of the pandemic in New York City, over 3000 transit workers have been infected and over 60 have died ${ }^{28}$, or roughly $2 \%$ of all confirmed cases and $1 \%$ of all fatalities. This fatality rate is particularly high considering that transit workers retire at age 55 .

\section{Significant Increased Risk Industries/Occupations}

"Essential" workers, including those in wholesale and retail trade, hotels and food service, infrastructure maintenance, essential manufacturing and construction are at risk of acquiring infection from infected co-workers and customers. Numbers of infected workers in these occupations are harder to estimate in the absence of any occupation-specific infection on mortality data to date, but appear to be significant ${ }^{29}$.

\section{Workers at high risk because of toxic occupational exposures and occupational diseases}

Occupational exposures to respiratory toxins such as vapors, gases, dust, and fumes (VGDF) or the presence of an occupational lung disease such as asbestosis, silicosis, other pneumoconiosis, COPD, and occupational asthma place workers at increased risk of mortality if they are infected by COVID-19. Individuals over the age of 65 who have a history of work in occupations such construction trades have an elevated prevalence of chronic occupational respiratory conditions and other comorbidities ${ }^{30}$.

\section{The importance of mild and early COVID-19 infection in spreading disease in workplaces}

As COVID-19 has spread to communities around the world, workplace risks have increased as symptomatic and asymptomatic workers with active COVID-19 infections continue to work in critical occupations supporting life, safety and infrastructure. Risks are greater in workplaces that require close, repeated or extended contact with persons with known or suspected COVID-19 infection. 
Risk assessment and disease containment is complicated by the fact that infected persons may have no symptoms but are still capable of transmitting infection to others. Community or workplace testing for COVID-19 infections is the only sure way to identify and isolate infected individuals to prevent spread of COVID-19. Current testing capacity is severely limited in many countries and results may not be available for several days.

Monitoring for fever is less specific as a means of identifying potentially infected persons. However, temperature measurement combined with verbal screening a useful interim measure. Contact tracing by public health authorities allows assessment of COVID-19 infection status in persons known to have had contact with an infected individual.

\section{ENVIRONMENTAL EXPOSURES AND SARS-CoV-2 INFECTION}

Multiple environmental exposures increase risk of coronavirus infection and severe disease. Environmental risk factors can act synergistically with occupational risk factors.

\section{List of Environmental Factors Known to be Associated with Increased Risk of COVID-19 and Related Mortality}

High Risk: smoking and probably vaping

Significantly Increased Risk: air pollution

\section{Smoking and Vaping}

A systematic review of studies examining the association between COVID-19 and smoking found that smokers were 1.4 times more likely than non-smokers ( $\mathrm{RR}=1.4,95 \% \mathrm{CI}: 0.98-2.00)$ to have severe outcomes with COVID-19 infection. Furthermore, smokers were approximately 2.4 times more likely to be admitted to an ICU, and need mechanical ventilation or die compared to non-smokers $(\mathrm{RR}=2.4,95 \% \mathrm{CI}: 1.43-4.04)^{31}$.

The WHO Framework Convention on Tobacco Control reports that among Chinese patients diagnosed with COVID-19 associated pneumonia, the odds of severe outcomes and death were 14 times higher among people with a history of smoking than among non-smokers ${ }^{32}$. The significantly higher rates of severe disease and death among men than women may be explained in part by higher rates of tobacco use among men ${ }^{33}$.

In previous pandemics, smoking was associated with increased mortality and more severe outcomes with other coronaviruses infections, such as MERS and SARS ${ }^{34}$.

Vaping devices cause inflammation in the lungs and airways. Users of vaping devices may be increased risk of severe outcomes and death from COVID-1935.

\section{Air Pollution}

During the SARS pandemic, studies of the relationship between air pollution and mortality found that patients from regions with moderate Air Pollution Index (API) had an 84\% increased risk of dying compared to those from regions with low APIs, and SARS patients from regions with high APIs were twice as likely to die from SARS as persons from regions with low APIs ${ }^{36,37}$. 
A recent study in the United States has reported a $15 \%$ increase in COVID-19-related mortality for each $1 \mu \mathrm{g} / \mathrm{m}^{3}$ increase in $\mathrm{PM}_{2.5}{ }^{*}$ air pollution concentration ${ }^{38}$. Analyses performed on data from 66 regions of Italy, Spain, France and Germany showed that $78 \%$ of the COVID-19 related deaths occurred in the five regions with the highest level of NO2 and air pollution $^{39}$. Poor air quality, nitrogen oxides and ozone, were also associated with COVID-19 lethality in different English regions ${ }^{40}$. Pre-existing conditions such as chronic lung and heart conditions are likely to further exacerbate this risk ${ }^{41}$.

An additional possible link between air pollution and COVID-19 infection is that airborne particulate matter can transport viruses ${ }^{42}$, and some early reports connect spread of COVID-19 infection to $\mathrm{PM}_{2.5}$ pollution ${ }^{43}$. Adsorption of the COVID-19 virus on airborne dust particles could contribute to long-range transport of the virus ${ }^{44}$.

\section{PREVENTION AND CONTROL OF COVID-19 INFECTION IN THE WORKPLACE}

\section{Work-related Recommendations Applicable until a Vaccine or Effective Treatment for COVID-19 is Provided}

- All at-risk workplaces should have a designated COVID-19 safety officer and COVID-19 safety plan.

- Practice frequent hand washing with soap and water or hand sanitizer.

- Physical separation must be maintained.

- All workers who can work remotely must do so.

- Only necessary travel can take place. Travelers must go into quarantine for 14 days upon return, unless documented by antibody testing to have immunity against COVID-19.

- Full protections against COVID-19 infection must be provided to all workers in jobs essential to societal functioning.

- Exceptions may be made for workers who are found to have immunity against COVID-19, documented by antibody testing.

- General Guidelines for worker protection can be found in Annex 1.

\section{General Procedures}

Once a pandemic is recognized, mitigation procedures become necessary to control the spread of disease and minimize societal damage. These include procedures to shut down and re-start work in the presence of active infection spread. In the absence of specific disease treatments or vaccines, effective mitigation efforts include quarantine, social distancing, work-at-home, non-essential business closing, use of PPE and increased laboratory testing and contact tracing to identify the infected. High-risk workers must be protected against infection and other work-related infections. Workers who have been exposed to SARS-CoV-2 in infected work settings have potential to spread infection to other workplaces and to carry the disease into their homes and communities ${ }^{45}$.

${ }^{*} \mathrm{PM}_{2.5}$ is a pollution index that scores fine particulate matter 2.5 micrometers or smaller. 
SARS-CoV-2 must be recognized as an occupational exposure risk and COVID-19 infection recognized as an occupational disease

SARS-CoV-2 must be recognized as an occupational exposure risk for which there is no known threshold or "safe" exposure. Consequently, employers have responsibility to establish maximum safeguards in workplaces to prevent exposures. Any occupationally exposed worker who develops COVID-19 infection must be presumed to have an occupationally acquired disease and occupational health and safety agencies appropriately notified. All such workers must receive wage replacement, payment for medical costs and workers' compensation as they would for any work-related disease. Any worker who is required to self-isolate and enter into quarantine, or who develops COVID-19 must continue to maintain wages and benefits.

Contacts of infected workers must be traced, tested and isolated.

Any worker who dies from COVID-19 infection and worked in a very high-risk or high-risk industry or occupation, or who otherwise is likely to have contracted the disease through occupational exposure, must be presumed to have died of an occupational disease and their survivors must receive all appropriate benefits.

Governments have responsibility to define COVID-19 infection as an occupational disease and to put appropriate prevention, follow-up and compensation programs in place.

\section{OSH duty holders are not relieved of their responsibility to protect workers during pandemics}

Any employer or organization whose workers may be at risk of exposure to COVID-19, is required to have in place a comprehensive occupational safety and health program that anticipates work-related risks and describes strategies for protection against such risks ${ }^{46}$. Safety and health protections must be the most feasible in accordance with the conditions of the work being performed. Workers have the absolute right to know about the risks they face from their work. These obligations remain in force even during a time of pandemic infection.

All at-risk workplaces must have a designated COVID-19 safety officer who is responsible for conducting hazard assessments and implementing necessary controls.

Workers at risk of COVID-19 infection in the current pandemic are not confined to the high-risk groups listed above and also include any person who has had physical contact, transports, or cleans up contamination from persons known or suspected to have COVID-19 infection. These include (but are not limited to) workers in transportation, security, construction, essential services and retail establishments, and waste management. Workplaces of all such workers must have comprehensive occupational safety and health programs in place as described above.

\section{Hierarchy of controls applies in protecting workers against COVID-19 infection}

Options to protect workers against COVID-19 exposures are limited, and must rely extensively on work practices and personal protective equipment (PPE). Unfortunately, within the hierarchy of control methods available in occupational safety and health, work practice rules and PPE are less desirable and less effective in safeguarding workers' health than 
engineering or administrative controls ${ }^{47}$. Therefore, an abundance of precaution must be adopted when relying on work practices and PPE, and this precautionary approach must be incorporated into allCOVID-19 safety and health plans ${ }^{48}$. Shortages of filtering facepiece disposable respirators have led, for example, to attempts to sanitize and re-use them even though these respirators are designed to be disposable and protective for only a single use. Such improvised procedures must be avoided if at all possible and their future recurrence prevented by maintaining adequate stockpiles of PPE ${ }^{49}$.

\section{Specific Procedures}

Hazard assessment and establishment of hazard controls in workplaces at risk of COVID-19 infection

Every essential workplace must perform a hazard assessment to determine whether infection risk applies and establish controls accordingly:

- In workplaces where there is little likelihood of infection the main controls will consist of preventing anyone with potential for infection to enter the workplace and to establish distancing procedures to keep workers separated, including in rest areas, eating areas and sanitary facilities.

- Workplaces where infected persons will or are likely to be served (e.g., mass transit, airports, retail shops, etc.), must have clearly defined safety and health plans. Areas of separation and separation procedures must be implemented.

- In workplaces where contact with infected persons is likely (first response, health care, mortuaries) decontamination procedures must apply in accordance with the procedures outlined below.

\section{Organization of Work/Work Practices}

Every essential workplace/organization must have a carefully articulated emergency procedure plan to prevent occupational exposure to COVID-19 and other infectious agents. These plans need to include provisions for shut-down of workplaces early in a pandemic, for maintaining essential operations during periods of active spread of infection, and for re-opening as numbers of new caws decline and the pandemic recedes.

- Secure entrance and egress. Only essential personnel are allowed to have access.

\section{- Screen each worker before allowing entry. See Annex 2}

for specific screening procedures.

- Case identification and contact tracing. If a worker is suspected of being infected, it is necessary to:

- Conduct appropriate diagnostic testing to assess presence of infection

- Isolate the worker in quarantine for up to14 days if proven or probably infected

- Identify other workers with whom the infected worker may have had close contact
Note:

For self-reporting to be reliable it is essential that employees are assured that their wages and benefits will be protected if they have to be isolated. 
- Perform COVID-19 risk assessment and diagnostic testing on those contacts to determine if they too must be isolated

\section{- Establish Exposure Zones and Work Practices.}

- In health care settings, zones at high risk of exposure to COVID-19 from infected patients or contaminated surfaces and equipment must be carefully defined and identified. Rigorously specified work practices and other measures that will avoid or minimize exposure must be implemented.

- COVID-19 treatment spaces, whether they are in the field or in medical centers must be designed and organized so that the delivery of patient care is performed using procedures that prevent exposure and minimize risk to workers.

- In other occupational settings where workers may have contact with persons potentially infected with SARS-CoV-2, zones must be established to the extent possible to minimize and isolate the physical areas where such contacts may be made. High-risk zones must be clearly demarcated and warning signs displayed.

- Maintain Physical Separation in the Workplace. Wherever possible a separation zone of at least 2 meters (6 feet) must be maintained between workers. If closer proximity is necessary, gloves, eye protection and respiratory PPE must be required.

- Sanitation and Maintenance of Disinfected Surfaces and Tools. CDC has issued disinfection recommendations that must be followed in all circumstances ${ }^{50}$.

\section{Principles of Personal Protective Equipment (PPE) Use}

Any worker with potential occupational exposure to COVID-19 must be provided with all necessary personal protective equipment (PPE).Individuals and groups of workers must be trained in the use of this equipment, including how to safely don (apply) and doff (remove) PPE.

A key principle in use of PPE is to consider PPE as a system that includes several types of clothing and equipment that must all be integrated and provide consistent protection. PPE must meet all recognized performance-based standards and be properly maintained.

A great deal of experience in use of PPE has been gained from high-hazard industries, and high-hazard health care settings such as EBV pandemics, where workers have had to rely heavily upon PPE protections and engineering and administrative controls were not available ${ }^{51}$.

Working in full PPE poses physiological risks to workers and increases risk of dehydration and heat stress. Rigorous attention must therefore be paid to limiting work shifts and to use of proper decontamination procedures during breaks between shifts. Sufficient time must be allowed at the beginning and end of each shift for donning, doffing and decontaminating PPE. 
Requirements for Personal Protective Equipment

Minimum specifications for selection of PPE are presented in Annex 3. Key PPE requirements are the following:

\section{Respirators}

NOTE: The terms "mask" and "respirator" have been used interchangeably in the COVID-19 pandemic, and "N95" has become a generic term for all disposable respirators, leading in many cases to inadequate protection. In this section, we present proper definition of these terms. And we emphasize that proper use of appropriate PPE is essential for worker protection. Further details on respirator specifications are provided in Annex 4.

A NIOSH-certified N95 Filtering Facepiece Respirator (FFR) (or similar respirators certified by official agencies in countries outside of the United States) is the minimal level of respiratory PPE required to protect workers against COVID-19 infection. This respirator has been certified to filter $95 \%$ of airborne particulates with a diameter of 0.3 microns. Individual SARS-CoV-2 particles (termed, "virions") have a diameter of approximately 0.05-0.2 microns ${ }^{52}$, but diameters of 70-90 nanometers (0.07-0.09 microns) have been reported ${ }^{48,49}$. N95 masks are at least $95 \%$ effective for particle sizes $0.1-0.3$ microns with higher efficiencies for larger particles; therefore, a certified $\mathrm{N} 95$ respirator is generally effective in filtering and capturing the SARS-CoV-2 virus, so long as the FFR is properly fitted ${ }^{49}$.

Note: Many respirators claim to provide $95 \%$ or greater filtration, but when tested rigorously are much less effective, even as lows $25 \% 53$.

All respirator use must be administered as part of a comprehensive Respiratory Protection Program (RPP). Requirements for these programs have been defined by the US Occupational Safety and Health Administration (OSHA) (OSHA Respiratory Protection Standard ${ }^{54}$, and by equivalent agencies in countries outside the USA. An RPP must contain provisions for training respirator users, for selecting, and sizing, and maintaining respirator equipment, and for conducting baseline and annual fit tests. Failure to provide a good fit significantly reduces the effectiveness of the respirator $^{55}$. The lack of an international harmonized standard on respirator selection, training and use impedes formulation of a global recommendation for a widespread hazard, such as COVID-19.

Where respirator supplies are limited, a number of decontaminating/sanitizing methods are being evaluated, including ultraviolet germicidal irradiation, vaporous hydrogen peroxide and moist heat. To date, limited research is available on use of these methods. Unresolved issues include the duration of treatment required to decontaminate respirators, the availability of required equipment, and detrimental performance effects on the filter, the electret, the seams, the exhalation valve (if included) and the strapping/suspension materials. Additionally, it must be ascertained that the procedure provides complete disinfection and not only a surface cleaning. Methods that must NOT be used include autoclaving, ethylene oxide sterilization or any process using harsh chemicals, as these will destroy the integrity of the respirator. While reuse of respirators is not optimal, minimal requirements suggested for reuse could include the worker doffing the FFR and placing it in a paper bag, where it will remain for a minimum of 5 days, allowing then for reuse by the same worker. 
FFRs can NOT be stored in plastic bags unless that plastic has been deemed non-electrostatic. If stored in a plastic bag (e.g. Ziplok), the electret will be inactivated and the FFR will no longer perform. All FFRs must be stored in paper bags or cardboard boxes when not in use.

APRs and PAPRs, as well as reusable faceshields, goggles, and protective garments can be disinfected and sanitized, and such work must be done in conformance with the manufacturer's recommendations. Additional advice must be sought from the manufacturer on appropriate cleaning agents, sanitizers, or disinfectants, and processes if not addressed in the instructions.

\section{Masks}

Mask categories include surgical masks and procedural masks. These are NOT respirators and must not be relied on for respiratory protection against the SARS-CoV-2 virus. They fit loosely to the face of the user and provide a limited barrier to splashes or aerosols. Some masks are being used as covers to extend service life of FFRs, but this increases breathing resistance.

Masks are designed to protect patients from the heath care provider. Surgical masks typically have fabric ties to secure to the face, while procedural masks typical use ear loops. Such facemasks should be evaluated for fluid resistance, particulate filtration efficiency, bacterial filtration efficiency, breathing resistance and flammability. An international and industry recognized standard for such masks is ASTM F2100, which covers their classifications, performance requirements, and test methods for the materials used in their construction ${ }^{56}$.

\section{Face and Ocular (Eye) Protection}

Contact of a worker's eyes with either SARS-CoV-2 liquid splashes, aerosols or through touching of the eye by contaminated fingers may transmit infection. Unless a full facepiece respirator or PAPR hood is used, a faceshield or safety googles must be worn in addition to a respirator to protect against such exposure. Faceshields will provide limited protection to the face and eyes from such direct contact.

\section{Skin Protection}

The SARS-CoV-2 virus is not transmissible through the skin. Like the facepiece, protective clothing will provide limited protection from infectious aerosols and liquid splashes. Appropriate protective clothing must have barrier capabilities that limit the penetration and/or absorption of contaminated liquids.

Gloves are clearly the most important item for dermal protection. There are numerous standards for different materials used in such examination gloves, including those for latex rubber, nitrile, and chloroprene. The National Fire Protection Association provides specific certification, design and performance requirements for protective clothing, including medical examination gloves ${ }^{57}$.

Double gloving must be considered when extensive liquid contact is expected. This procedure will further protect if the outer glove is perforated while performing patient care and will also assist in doffing by removing the contaminated outer glove. 


\section{WORK-RELATED SURVEILLANCEAND REPORTING}

Case identification and contact tracing are essential components of any public health response to COVID-19. Workplaces are important cogs in any surveillance system. Any person arriving at an essential workplace with possible symptoms of COVID-19 must be referred immediately to public health authorities for evaluation and possible contact tracing.

All COVID-19 reporting systems must obtain information on occupation and industry as essential reporting elements to be linked to infection frequency and severity of disease outcomes. The Council of State and Territorial Epidemiologists in the USA has released a recommended practice for the collection of data on occupation and industry during the COVID-19 pandemic ${ }^{58}$. Such data will enable a more informed response in future outbreaks.

\section{NEED FOR A BETTER GLOBAL RESPONSE}

For over two decades, repeated calls have urged governments, health care systems around the world and their workers to become better prepared for outbreaks of new and emerging infections. In 2004, the International Commission on Occupational Health (ICOH) and the International Social Security Association (ISSA) called for a "systematic occupational risk prevention program" to include training regarding work risks and the provision of protective measures, as an integral components ${ }^{59}$. In 2007, WHO declared that the loss of workers to preventable diseases because of inadequate safeguards threatens the viability of health care systems ${ }^{60}$.

The current COVID-19 pandemic has demonstrated a woeful lack of preparedness in many governments and health care organizations. This is the consequence of decades of neglect of public health, failure to plan for the rapid spread of pandemics in today's highly interconnected world, and failure to heed early warnings. Staffs and budgets of public health agencies have been cut ${ }^{61}$. Emergency stockpiles of medications and supplies have been disbanded. Training has been neglected. Contingency plans have not been developed. Leadership capacity in public health has eroded. The resulting failures have been stark and spectacular, specifically:

- No serious limits on global travel and noscreening of global travelers was implemented until the pandemic had already spread to virtually every country in the world. This resulted in health care systems being overwhelmed and essential supplies being rapidly depleted.

- The failure of a number of nations to adopt any measures of social isolation and quarantine resulted in continued unfettered domestic spread long after international spread had begun tobe contained.

- The failure of many nations to develop and deploy a reliable COVID-19 test made it impossible to implement effective detection and contact tracing strategies.

The price of this neglect is being paid by us all, but the highest price is being paid by the brave and dedicated workers who labor each day to protect our societies, while placing themselves at risk.

$* * * * *$

In conclusion, the Collegium Ramazzini urges the global community and every country to urgently establish preventive measures that will limit environmental and occupational exposures that might increase risk of COVID-19 infection. 
The international community and all countries must act also to ensure that workers and the general population in COVID-19 exposure zones receive the full protections to which they are entitled, and to ensure that health systems are better prepared to confront future outbreaks of emerging infectious diseases.

Looking to the future, the Collegium Ramazzini calls on international standard-setting organizations to urgently develop a single consistent set of standards for personal protective equipment for that will protect these front-line workers, including first responders and health care personnel against exposures to biological hazards and airborne pathogens in future pandemics. Such a PPE package must specify and mandate criteria for product performance, fit and function. This standard PPE package must be properly certified by occupational health and safety agencies in countries around the world.

\section{Annex 1 \\ General Guidelines for Workers ${ }^{62}$}

- Don't go to work if you are feeling sick.

- Don't go to work if you have a fever.

- Don't go to work if you have a cough or shortness of breath.

- Avoid contact with sick people.

- Don't shake hands when greeting others.

- Stop work and report any possible unsafe situation to your supervisor

- Comply with all PPE requirements.

- Avoid large gatherings or meetings of 10 people or more.

- Stay at least 2 meters away from others on job sites and in gatherings, meetings, and training sessions.

- Wear a face mask to protect others or cover your mouth and nose with tissues if you cough or sneeze or do so into your elbow.

- Avoid touching your eyes, nose, or mouth with unwashed hands.

- Clean your hands often by washing them with soap and water for at least 20 seconds. When hand washing isn't available, use an alcohol-based hand sanitizer with greater than $60 \%$ ethanol or $70 \%$ isopropanol. Soap and water must be used if hands are visibly dirty.

- Clean your hands frequently, including before and after going to the bathroom, before eating, and after coughing, sneezing, or blowing your nose.

- Bring food and water bottles from home to the job site and do not share.

- Drive to worksites or parking areas by yourself - no passengers or carpooling.

- Wipe down interiors and door handles of machines or vehicles, and the handles of equipment and tools that are shared, with disinfectant prior to entering.

- Prevent family exposure to virus by immediately removing footwear and clothing upon returning home. In hospital and first responder settings, protocols must be developed addressing the changing out of work clothing, scrubs or uniforms at worksite. 


\section{Annex 2}

\section{Verbal Screening and Temperature Check Protocols}

Verbal screening and temperature checks must be conducted at the start of each shift to identify and isolate potential COVID-19 carriers and their immediate workplace contacts for further evaluation. The CDC has provided verbal screening questions for COVID-19 symptoms and for contacts of known cases, and a safe temperature check procedure:

- Verifying immunity. Workers who can establish with a valid antibody test that they are immune require no further screening.

- Verbal screening for symptoms of COVID-19 and contact with COVID-19 cases must include the following questions:

- Today or in the past 24 hours, have you had any of the following symptoms?

- Fever, felt feverish, or had chills?

- Cough?

- Difficulty breathing?

- In the past 14 days, have you had contact with a person known to be infected with the novel coronavirus (COVID-19)?

- The following is a protocol to safely check an individual's temperature:

- Perform hand hygiene.

- Put on a face mask, eye protection (goggles or disposable face shield that fully covers the front and sides of the face), gown/ coveralls, and a single pair of disposable gloves.

- Check individual's temperature. If possible, use a non-contact/remote detector. If performing a temperature with a nonremote detector check on multiple individuals, ensure that a clean pair of gloves is used for each individual and that the thermometer has been thoroughly cleaned in between each check. If disposable or non-contact thermometers are used and the screener did not have physical contact with an individual, gloves do not need to be changed before the next check. If non-contact thermometers are used, they must be cleaned routinely as recommended by CDC for infection control.

- Remove and discard PPE using methods to avoid contamination.

- Perform hand hygiene.

Annex 3

Minimum Recommended Guidance on PPE for Workers Involved in Covid-19 Deployment and Treatment ${ }^{63}$

\begin{tabular}{clll}
\hline \multicolumn{1}{c}{ Type of protection } & \multicolumn{1}{c}{ Preferred or ideal } & \multicolumn{1}{c}{ Minimum } & \multicolumn{1}{c}{ Other factors } \\
\hline Respiratory & NIOSH approved P100 filtering & NIOSH approved N95 filtering \\
& $\begin{array}{l}\text { facepiece respirator; or } \\
\text { Reusable elastomeric facepiece }\end{array}$ & $\begin{array}{l}\text { If surgical/procedure mask used } \\
\text { facepiece }\end{array}$ & (must meet ASTM F2100) Level \\
& with P100 filters; or & Europe equivalents: \\
& PAPR with HEPA filters & FFP2 $\approx$ N95 \\
& & FFP3 $\approx$ P100 \\
\hline
\end{tabular}




\begin{tabular}{|c|c|c|c|}
\hline Type of protection & Preferred or ideal & Minimum & Other factors \\
\hline Ocular & $\begin{array}{l}\text { ANSI Z87.1 N3 or N5 rated } \\
\text { goggles; or } \\
\text { Full facepiece respirator }\end{array}$ & $\begin{array}{l}\text { ANSI Z87.1 compliant } \\
\text { Disposable or reusable } \\
\text { faceshield; or } \\
\text { Safety glasses }\end{array}$ & $\begin{array}{l}\text { Attached shields on surgical } \\
\text { or procedure masks are not } \\
\text { effective by themselves (wear } \\
\text { with safety glasses) }\end{array}$ \\
\hline Dermal - hand & $\begin{array}{l}\text { Examination gloves meeting } \\
\text { ASTM D6319 (nitrile), ASTM } \\
\text { D6977, or NFPA 1999; } \\
\text { Double gloving offers additional } \\
\text { physical protection }\end{array}$ & $\begin{array}{l}\text { Examination gloves meeting } \\
\text { ASTM D3578 (latex) ; or } \\
\text { cleaning elastomeric or coated } \\
\text { work gloves }\end{array}$ & $\begin{array}{l}\text { Avoid glove liners or cloth-based } \\
\text { gloves. } \\
\text { Always thoroughly clean hands } \\
\text { with soap and water or hand } \\
\text { sanitizer after use }\end{array}$ \\
\hline Dermal - body & $\begin{array}{l}\text { Isolation gowns that meet Level } \\
4 \text { criteria in AAMI PB70 and } \\
\text { ASTM F3352; or } \\
\text { Single use garments or } \\
\text { ensembles certified to NFPA } \\
1999\end{array}$ & $\begin{array}{l}\text { Any protective garments } \\
\text { offering passing viral } \\
\text { penetration resistance per } \\
\text { ASTM F1671 with adequate } \\
\text { integrity, strength, and } \\
\text { durability for intended use }\end{array}$ & $\begin{array}{l}\text { Lesser barrier clothing may } \\
\text { result in contamination of } \\
\text { underlying uniform or work } \\
\text { clothing but may be suitable for } \\
\text { light exposures. } \\
\text { European equivalent: } \\
\text { ISO } 16604 \text { at } 3.5 \mathrm{kPa} \text { per EN } \\
14126 \approx \text { ASTM F1671 and } \\
\text { NFPA } 1999\end{array}$ \\
\hline
\end{tabular}

\section{Annex 4 \\ Specifications for Respirators to Protect Workers at Risk of Coronavirus Infection}

The filtering media (middle layer) used by filtering facepiece respirators (FFRs) are typically a non-woven (melt-blown) electrostatically charged polypropylene microfiber, which allows for airborne particulate capture through diffusion, interception and impaction collection which is then enhanced by electrostatic attraction. The electrostatically-charged filter media offer a significant capture of particulates without increasing breathing resistance. The media is termed the electret and its importance must be considered in any decontamination process that would reduce the electrostatic change. Hence, the reason for FFRs were designed for one time use and then disposal and not intended for cleaning or for long term usage.

Some disposable FFRs contain an exhalation valve. An exhalation valve reduces exhalation resistance, which makes it easier to breathe (exhale). However, an infected worker or patient must not use an FFR with an exhalation valve.

A P-100 disposable FFR or a respirator with a higher level of respiratory protection, including a full or half facepiece air purifying respirator (APR) or powered air purifying respirator (PAPR) with a High Efficiency Particulate Air (HEPA) filter/canister must be considered the optimal respiratory protection during this pandemic. Further these respirators must be used during any aerosolgenerating procedures (whether treating patients in pre-hospital environments (e.g. ambulance) or in the hospital).

Filtering facepiece respirators are manufactured and sold in nine different types, depending on filtering efficiency and environment where they are used. These particulate respirators are also known as "air-purifying respirators" because they protect by filtering particles out of the air as you breathe. These respirators protect only against particles - not gases or vapors. Since airborne biological agents such as bacteria or viruses are particles, they can be filtered by particulate respirators. Respirators that filter out at 
least 95\% of airborne particles during "worse case" testing using a "most-penetrating" sized particle are given a "95" rating. Those that filter out at least 99\% receive a "99" rating. And those that filter at least 99.97\% (essentially 100\%) receive a "100" rating. Respirators in this family are rated as $\mathrm{N}$, $\mathrm{R}$, or $\mathrm{P}$ for protection against oils. This rating is important because some industrial oils can degrade the filter performance so it does not filter properly. Respirators are rated "N," if they are not resistant to oil, "R" if somewhat resistant to oil, and "P" if strongly resistant (oil proof) or if conditions unknown. Currently there are no NIOSH approved R-99, P-99 or R-100 disposable FFR respirators. However, for respirator usage during this pandemic, "oil environments" have little relevance in the health care setting. N95 respirators have to meet a 95\% filtration efficiency and the P-100 a 100\% (99.97\%). So, as a comparison of filtration efficiency, a P-100 will allow a maximum of $0.03 \%$ penetration and an N-95 will allow 5\%. Therefore, a P-100 filter will be more than 100 times effective at removing the COVID-19 virus.

The P-100 filter efficiency recommendation is consistent with NIOSH recommendations for emergency response to biological agent incidents ${ }^{64}$. Additionally the recommendation is consistent with federal OSHA regulations that state "where workers are exposed to a hazard that would require the use of a respirator with HEPA filtration, the appropriate class of respirator under the 42 CFR Part 84 certification is the Type 100 (N-100, R-100, or P-100).” The recommendation is also consistent with the specifications contained in the World Health Organization's guidance during the SARS pandemic ${ }^{65}$.

Further classification of NIOSH approved FFRs include US Food and Drug Administration (FDA) clearance for FFR use in medical settings. FDA recognized the unique risk in such environments including the potential for surgical fires, blood and body fluid splatters, and potential risk of adverse skin reaction to the wearer. In addition to the particulate filtration efficiency certified by NIOSH, FDA cleared FFRs are tested by the manufacturer and data is then provided to the FDA on bacterial filtration efficiency, flammability and biocompatibility. Unlike NIOSH, FDA does not test and certify these additional requirements, but clears them based on review of the manufacturers' submitted test data.

When properly fitted, maintained and used, a FFR (or an APR or PAPR with a HEPA filter) provides protection from inhalation of infectious airborne droplets. Again, the P-100 respirator or an APR or PAPR with a HEPA filter provides the highest levels of aerosol protection as compared to respirators rated only for particulate (aerosol) protection. However, there are NO safe exposure levels (i.e., the amount you can inhale without adverse health effects) for biological aerosols. Respirators can reduce inhalation exposures but cannot eliminate the risk of contracting infection or developing illness or disease. Additionally, the type of respirator facepiece and filter class required varies depending upon one's activities and risk of exposure.

Further, a respirator, regardless of type, will only trap the COVID-19 virus, it will not destroy or inactivate it. It is not currently known how long the virus will survive on the filtering medium and the potential for fomite transmission.

Additionally, disposable FFRs must have seal enhancing elastomeric components (e.g. foam, rubber or plastic respirator to face seals) and must be equipped with two or more adjustable suspension straps. Without these components it is difficult to obtain and maintain a seal in the workplace.

All disposable FFRs, as well as APRs and PAPRs, must also be certified by NIOSH. NIOSH-approved disposable respirators are marked with the manufacturer's name, the part number (P/N), the level of protection provided by the filter (e.g., P-100), and "NIOSH." This information is printed on the facepiece, exhalation valve cover, or head straps. If a NIOSH marking is not on the respirator, it is not certified by NIOSH and must not be used. Since respirator classes are designated for use in certain environments with the P-100 being the most universal, NIOSH has designated only the P-100 respirator with magenta color coding 
and markings. Compounding this problem, there are many fake N95s on the market that have not been certified and do not meet certification standards.

In addition to NIOSH certification, there are numerous FFRs available that have been manufactured utilizing standards developed by other international governing bodies.

\begin{tabular}{lcc}
\hline \multicolumn{1}{c}{ Product Classifications } & Jurisdiction & Performance Standard \\
\hline P2 (95), P3 (99) & Australia/New Zealand & AS/NZS 1716:2012 \\
PFF2 (95), PFF3 (99) & Brazil & ABNT/NBR 13698:2011 \\
KN95, KP95, KN100, KP100 & China & GB2626-2006, GB2626-2019 \\
FFP2 (95), FFP3 (99) & Europe & EN 149-2001 \\
DS/DL2 (95), DS/DL3 (0) & Japan & JMHLW-2000 \\
Korea 1st class (95) & Korea & KMOEL-2017-64 \\
N95, P95, R95,N99, P99, R99, N100, P100, R100 & Mexico & NOM-116-2009 \\
\hline
\end{tabular}

Note: The parenthetical information provided in the above table denotes filter performance of the products listed. However, many of these jurisdictions do not "certify" their products. Additionally, limited information is publicly available on manufacturers' quality control systems or on the quality control of specific products. Additionally, no information exists regarding the effectiveness of respirators after they have left the manufacturers' facilities. NIOSH has recently (2/2020) undertaken a limited assessment of respirators' claimed filtering capabilities. Counterfeit FFNs have been reported, especially with KN95 respirators.

The effectiveness of any respirator is highly dependent on proper fitting to users' faces. Respirators that leak offer virtually no respiratory protection. Proper sizing of respirators is also critically important. Improper sizing (adjusting too tight) may lead to leakage as well as to face bruising and trauma.

Selection of a respirator manufacturer must be based on the manufacturer's ability to provide a range of sizing options for a variety of facial sizes that should ideally include small, small/medium, standard, medium, medium/large, large and x-large sizes.

\section{REFERENCES}

1. Fauci AS., H. Lane HC, M.D., and Redfield RR. COVID-19 - Navigating the Uncharted. N Eng J Med 382:1268-69, 2020.

2. Johns Hopkins University and Medicine's Coronavirus Resource Center at https://coronavirus.jhu.edu/map.html.

3. https://www.who.int/news-room/commentaries/detail/modes-of-transmission-of-virus-causing-COVID-19-implications-for-ipcprecaution-recommendations.

4. Bourbouida L. Turbulent Gas Clouds and Respiratory Pathogen Emissions - Potential Implications for Reducing Transmission of COVID-19. JAMA. Published online March 26, 2020.

5. Van Doremalen N, Morris DH, Holbrook G. et al. Aerosol and Surface Stability of SARS-CoV-2 as Compared with SARSCoV-1 N Engl J Med 2020; 382:1564-1567. https://doi.org/10.1056/nejmc2004973.

6. Xiao W, Nethery RC, Sabath N, Braun D, Dominici F. Exposure to air pollution and COVID-19 mortality in the United States. April 5, 2020. MedxRiv: https://www.medrxiv.org/content/10.1101/2020.04.05.20054502v1.

7. Ranshoff RM. Immunology: Licensed in the lungs. Nature. 2012;488(7413):595-596.

8. DaneshYazdi M, Wang Y, Di Q, Zanobetti A, Schwartz J. Long-term exposure to PM2.5 and ozone and hospital admissions of Medicare participants in the Southeast USA. Environ Int. 2019;130:104879. 
9. Leth-Larsen R, Zhong F, Chow VT, Holmskov U, Lu J. The SARS coronavirus spike glycoprotein is selectively recognized by lung surfactant protein D and activates macrophages. Immunobiology 2007;212(3):201-211.

10. WHO. 2020. Report of the WHO-China joint mission on coronavirus disease 2019 (COVID-19). Available on-line: https://www. who.int/docs/default-source/coronaviruse/who-china-joint-mission-on-COVID-19-final-report.pdf.

11. Bialek S, Boundy E, Bowen V, Chow N, Cohn A, Dowling N, et al. 2020. Severe outcomes among patients with coronavirus disease 2019 (COVID-19) - United States, February 12-March 16, 2020. Morbidity and Mortality Weekly Report MMWR 69:343-346.

12. Guan WJ, Ni ZY, Hu Y, Liang WH, Ou CQ, He JX, Liu L, Shan H, Lei CL, Hui DS, Du B. Clinical characteristics of coronavirus disease 2019 in China. New England Journal of Medicine. 2020 Feb 28.

13. Lan FY, Wei CF, Hsu YT, Christiani DC, Kales SN. Work-related COVID-19 transmission. MedRxiv. 2020. doi: https://doi.org/ 10.1101/2020.04.08.20058297.

14. Smithfield Foods Becomes Largest Coronavirus Hotbed In United States, South Dakota. https://www.forbes.com/sites/alexandrasternlicht/2020/04/16/smithfield-foods-becomes-largest-coronavirus-hotbed-in-united-states-south-dakota-governor-yet-tomandate-stay-home-order/\#7ff4bb792143.

15. Dorn AV, Cooney RE, Sabin ML. COVID-19 exacerbating inequalities in the US. The Lancet, 395:1243-1244, 2020. doi: https:// doi.org/10.1016/S0140-6736(20)30893-X.

16. Blumberg HM, Watkins DL, Berschling JD, et al. Preventing the Nosocomial Transmission of Tuberculosis. Ann Intern Med. 1995;122:658-663. doi: https://doi.org/10.7326/0003-4819-122-9-199505010-0000.

17. Chan-Yeung, M. Severe Acute Respiratory Syndrome (SARS) and Healthcare Workers, International Journal of Occupational and Environmental Health, 10:4, 421-427, doi: https://doi.org/10.1179/oeh.2004.10.4.421.

18. Koh D, Sng J. Lessons from the past: perspectives on severe acute respiratory syndrome. Asia Pac J Public Health. 2010 Jul;22 (3 Suppl) :132S-136S. doi: https://doi.org/10.1177/1010539510373010.

19. Zumla, A, et al. Infection control and MERS-CoV in health-care workers. The Lancet, Volume 383, Issue 9932, 1869-1871, 2014.

20. World Health Organization. Middle East respiratory syndrome coronavirus (MERS-CoV) Summary of Current Situation July 2019. https://apps.who.int/iris/bitstream/handle/10665/326126/WHO-MERS-RA-19.1-eng.pdf?ua=1.

21. World Health Organization. Health worker Ebola infections in Guinea, Liberia and Sierra Leone: preliminary report, 2015. Available: https://www.who.int/csr/resources/publications/ebola/health-worker-infections/en/.

22. Wu Z, McGoogan JM. Characteristics of and Important Lessons from the Coronavirus Disease 2019 (COVID-19) Outbreak in China: Summary of a Report of 72314 Cases from the Chinese Center for Disease Control and Prevention. JAMA. Published online February 26, 2020.

23. McMichael TM, Clark S, Pogosjans et al. COVID-19 in a long-term care facility in King County, Washington, February 27 March 9, 2020. MMWR 2020;69:339-342. doi: https://doi.org/10.15585/mmwr.mm6921e1.

24. Burrer SH, de Pseriod MA, Hughes MH et al. Characteristics of Health Care Personnel with COVID-19 - United States, February 12-April 9, 2020MMWR Weekly / April 17, 2020 / 69(15);477-481. https://doi.org/10.15585/mmwr.mm6915e6.

25. Cruise ships stuck at sea 'indefinitely' with sick onboard amid coronavirus pandemic. https://fortune.com/2020/04/01/cruiseships-out-of-florida-coronavirus-stuck-at-sea/. 
26. Collegium Ramazzini Statement No. 16. The Safety and Health of Migrant Labour. 2011. http://www.collegiumramazzini.org/ download/16_SixteenthCRStatement (2011).pdf.

27. Prof. David Koh, Brunei University, personal communication (email), 12 April 2020.

28. https://www.pix11.com/news/coronavirus/COVID-19-killing-nyc-transit-workers-at-staggering-rate.

29. Koh D. Occupational risks for COVID-19. Occl Med 2020;70(1):3-5, https://doi.org/10.1093/occmed/kqaa036.

30. Ringen K, Dement J, Hines S, Quinn P, Chen A, Haas S. Mortality of older construction and craft workers employed at Department of Energy nuclear sites: Follow-up through 2016. Am J Ind Medicine, 2019;62:742-754. https://doi.org/10.1002/ajim.23018.

31. Vardavas CI, Nikitara K. 2020. COVID-19 and smoking: A systematic review of the evidence. Tob Induc Dis 18:20.

32. WHO.Increased risk of COVID-19 infection amongst smokers and amongst waterpipe users. March 13, 2020. https://untobaccocontrol.org/kh/waterpipes/COVID-19/.

33. Guan WJ, Ni ZY, Hu Y, Liang WH, Ou CQ, He JX, Liu L, Shan H, Lei CL, Hui DS, Du B. Clinical characteristics of coronavirus disease 2019 in China. New England Journal of Medicine. 2020 Feb 28.

34. Nam HS, Park JW, Ki M, Yeon MY, Kim J, Kim SW. 2017. High fatality rates and associated factors in two hospital outbreaks of MERS in Daejeon, The Republic of Korea. Int J Infect Dis 58:37-42.

35. Hwang, J.H., Lyes, M., Sladewski, K. et al. Electronic cigarette inhalation alters innate immunity and airway cytokines while increasing the virulence of colonizing bacteria. J Mol Med 94, 667-679 (2016). https://doi.org/10.1007/s00109-016-1378-3.

36. Cui Y, Zhang ZF, Froines J, Zhao J, Wang H, Yu SZ, et al. 2003. Air pollution and case fatality of SARS in the people's republic of china: An ecologic study. Environmental health: a global access science source 2:15.

37. Cui, Op. cit.

38. Xiao W, Nethery RC, Sabath N, Braun D, Dominici F. Exposure to air pollution and COVID-19 mortality in the United States. April 5, 2020. MedxRiv: https://www.medrxiv.org/content/10.1101/2020.04.05.20054502v1.

39. Ogen Y. Assessing nitrogen dioxide (NO2) levels as a contributing factor to coronavirus (COVID-19) fatality [published online ahead of print, 2020 Apr 11]. Sci Total Environ. 2020;726:138605.

40. Marco Travaglio, Rebeka Popovic, Yizhou Yu, Nuno Leal, L. Miguel Martins. Links between air pollution and COVID-19 in England. medRxiv 2020.04.16.20067405; doi: https://doi.org/10.1101/2020.04.16.20067405.

41. EEA. 2020. Reflecting on climate-neutrality ambitions in europe in times of COVID-19. European Environmental Agency 20 Mar 2020.

42. Chen G, Zhang W, Li S, Zhang Y, Williams G, Huxley R, et al. The impact of ambient fine particles on influenza transmission and the modification effects of temperature in china: A multi-city study. Environment international 2017;98:82-88.

43. Setti L. 2020. Evaluation of the potential relationship between particulate matter (pm) pollution and COVID-19 infection spread in Italy. SIMA Report 2020.

44. Qu G, Li X, Hu L, Jiang G. 2020. An imperative need for research on the role of environmental factors in transmission of novel coronavirus (COVID-19). Environmental Science \& Technology. https://www.medrxiv.org/content/10.1101/2020.04.05.20054502v1.

45. Sixteenth Collegium Ramazzini Statement. The Safety and Health of Migrant Labour, 2011.

46. International Labor Organization. ILO Convention 155 - Occupational Safety and Health Convention, 1981.

47. Institute of Medicine, Op. cit. 
48. Brosseau LM and Jones R. Commentary: Health workers need optimal respiratory protection for Ebola. http://www.cidrap. umn.edu/news-perspective/2014/09/commentary-health-workers-need-optimal-respiratory-protection-ebola.

49. Herron JT, Hay-David AGC, Gillian AD, Brennan PA. Personal protective equipment and COVID 19 - a risk to healthcare staff? Br J Oral Maxillofac Surg. 2020 Apr 13. doi: https://doi.org/10.1016/j.bjoms.2020.04.015.

50. See https://www.cdc.gov/coronavirus/2019-ncov/community/organizations/cleaningdisinfection.html.

51. See e.g., HAZWOPER PPE Requirements: Levels of Protection. http://safetydailyadvisor.blr.com/2013/07/hazwoper-ppe-requirements-levels-of-protection.

52. Chen N, Zhou M, Dong X, Qu J, Gong F, Han Y, et al. 2020. Epidemiological and clinical characteristics of 99 cases of 2019 novel coronavirus pneumonia in Wuhan, China: a descriptive study. The Lancet. 395(10223):507-513. doi: https://doi.org/10.1016/S01406736(20)30211-7.

53. NPPTL Respirator Assessments to Support the COVID-19 Response. International Assessment Results - Not NIOSH-approved. Updated April 29, 2020. https://www.cdc.gov/niosh/npptl/respirators/testing/NonNIOSHresults.html.

54. 29 CFR 1910.134, http://www.osha.gov.

55. Serfozo N, Ondráček J, Zíková N, Lazaridis M ,Ždímal V. Size-Resolved Penetration of Filtering Materials from CE-Marked Filtering Facepiece Respirators. Aerosol and Air Quality Research, 17: 1305-1315, 2017. doi: https://doi.org/10.4209/aaqr.2016.09.0390.

56. ASTM F2100-19, Standard Specification for Performance of Materials Used in Medical Face Masks, ASTM International, West Conshohocken, PA, 2019, www.astm.org.

57. NFPA 1999, Standard on Protective Clothing and Ensembles for Emergency Medical Operations, 2018 edition.

58. Council of State and Territorial Epidemiologists. Recommended Interim Guidance for Collecting Employment Information About COVID-19 Cases. April 16, 2020.

59. International Commission on Occupational Health (ICOH) and the International Social Security Association (SSA). Recommendations for protection health care workers' health. Newsletter 6, 2004. http://ohtc.med.uoeh-u.ac.jp/inform/ICOHnewsletter/ICOH\%20newsletter\%20OH\%20for\%20HCW\%206\%202004.pdf.

60. World Health Organization (WHO), Everybody's Business; Strengthening Health Systems to Improve Health Outcomes. WHO's Framework for Action. 2007. http://www.who.int/healthsystems/strategy/everybodys_business.pdf?ua=1.

61. https://www.statnews.com/2020/04/05/deficit-public-health-workers-no-way-to-fight-covid-19.

62. Derived from https://www.cpwr.com/sites/default/files/CPWR_Guidance_on_COVID.pdf.

63. Baxter, CM and Stull, JO. Minimum Recommended Guidance on Protection and Decontamination for First Responders Involved in CVOID-19 Cases - Quick Response Guide, March 2020.

64. http://www.cdc.gov/niosh/unp-intrecppe.htm.

65. Hospital Infection Control Guidance for SARS.

Corresponding author: Daniela Pelclova, Department of Occupational Medicine, First Faculty of Medicine, Charles University, General University Hospital in Prague, Na Bojisti 1, 12000 Prague, Czech Republic (e-mail: daniela.pelclova@lf1.cuni.cz).

From the Editor: the text is published in its original form, without any edition. Several other journals around the world are co-publishing this Statement as there is an urgent need to advise the health professions and the global public of this critical information.

This work is available in Open Access model and licensed under a Creative Commons Attribution-NonCommercial 3.0 Poland License - http://creativecommons.org/licenses/by-nc/3.0/pl/deed.en. 